\title{
EFFECTS OF PSYCHOLOGICAL INTERVENTION VERSUS PHARMACOLOGICAL TREATMENT IN PATIENTS WITH BORDERLINE PERSONALITY DISORDER DURING EMOTIONAL INSTABILITY CRISIS
}

\author{
S.S. Sanchez ${ }^{1}$, G. Ruiz M. ${ }^{1}$, M.O. Solis' ${ }^{1}$, F. Vilchez E. ${ }^{1}$. \\ IUGC Salud Mental Jaen, Complejo Hospitalario de Jaen, Spain.
}

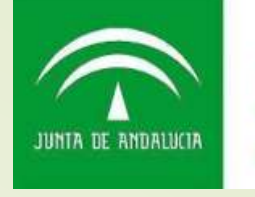

Servicio Andaluz de Salud
CONSEJERIA DE SALUD

COMPLEO HOSPTALARRIO DE JAEN

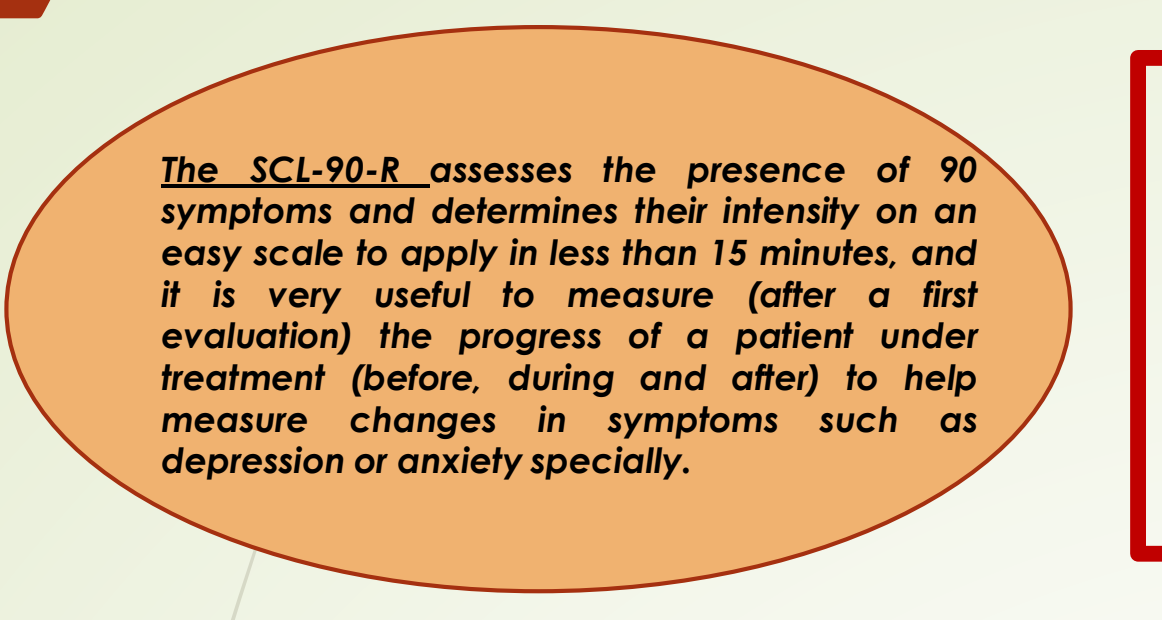

Borderline Personality Disorder is characterized by emotional instability, extremely polarized and dichotomous thinking, impulsivity and chaotic interpersonal relationships. "Combined treatment with psychotropic drugs and psychotherapy, often does not prevent consultations in crisis situations. The most common symptoms they present can be measured with the SCL-90R inventory, in the items of anxiety, depression and hostility.

Objective:

To compare the efficacy of the psychological intervention in Borderline Personality Disorders (BPD) patients versus the adjustment of psychotropic drugs in emergency situations, in order to avoid changes in the usual pharmacological treatment of these patients.

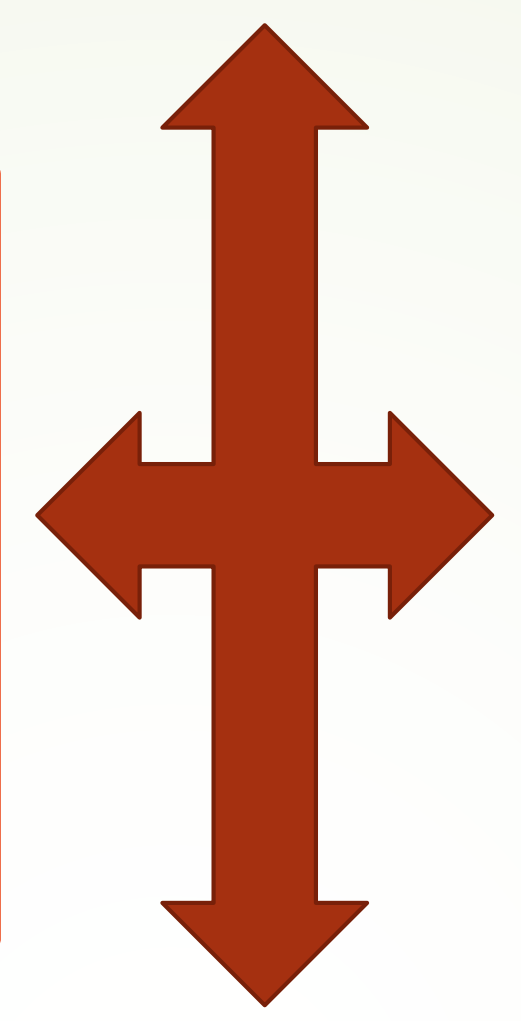

\section{Background}

Patients with BPD are complex patients who frequently ask for attention in reaction to personal conflicts ("crisis") and demand soothing medication to solve the situation. Some common psychotropic drugs used are benzodiazepines (BZP) and antidepressants, which involve risks of self-medication, abuse or impulsive intake.

\section{Materials and Methods:}

Sample of 20 patients with TPB between 18 and 45 years.

Somatizations (SOM

- Interpersonal sensitivity

(SI)

- Depression (DEP)

- Anxiety (ANS)

- Hostility (HOS)

- Phobic Anxiety (FOB)

Paranoid Ideation (PAR)

Psychoticism (PSIC)

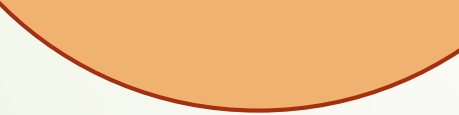
r
-Symptoms Scale-Check-t anxiety and depression.

-Score levels: 0-9 points (mild symptoms), 10-19 (moderate), 20-28 (severe). -Techniques of brief psychotherapy in "crisis" situation during the attention. -After the intervention, patients with score >20 points are referred to their Mental Health Center preferably for re-evaluation.

\section{Results:}

-Scores SCL-90-R between 14 and 28 points (average: 20.9 points).

-Most of patients exceeded 20 points in the emergency room (60\%); after attention only 2 patients (10\%).

-Nearly $50 \%$ of patients required pharmacological treatment (benzodiazepines or antipsychotics) during the crisis.

-About $40 \%$ ( $39 \%$ of women, $43 \%$ of men) required pharmacological adjustment after psychological intervention.

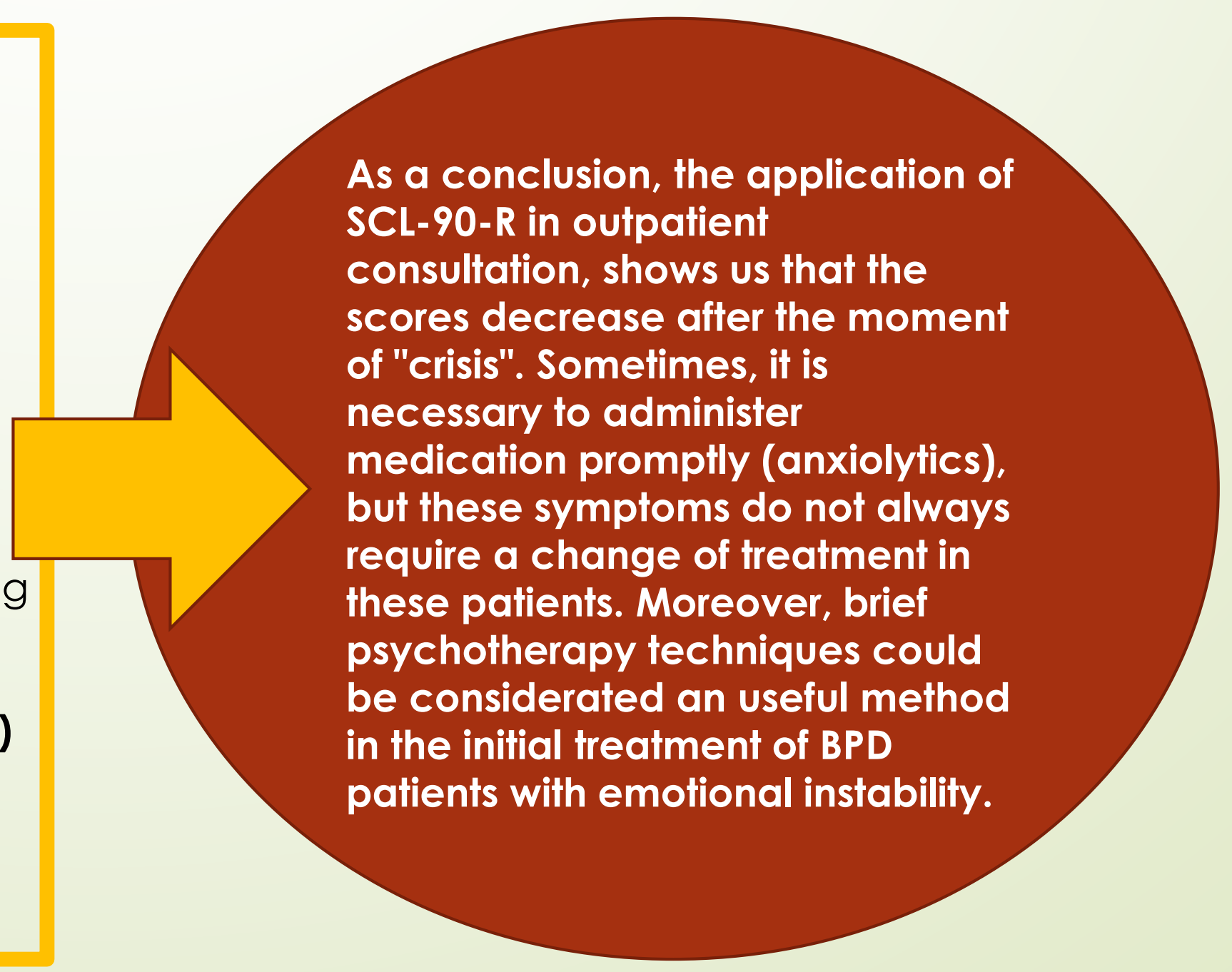

